\title{
Prognostic factors for different outcomes in patients with metastatic spinal cord compression from cancer of unknown primary
}

\author{
Sarah Douglas ${ }^{1}$, Stefan Huttenlocher ${ }^{1}$, Amira Bajrovic ${ }^{2}$, Volker Rudat ${ }^{3}$, Steven E Schild ${ }^{4}$ and Dirk Rades ${ }^{\text {** }}$
}

\begin{abstract}
Background: Patients with cancer of unknown primary account for $10 \%$ of patients with metastatic spinal cord compression (MSCC). This retrospective study was performed to identify prognostic factors for functional outcome, local control of MSCC, and survival in 175 of such patients treated with radiotherapy alone.

Methods: Investigated were nine potential prognostic factors including age, gender, Eastern Cooperative Oncology Group performance score (ECOG-PS), number of involved vertebrae, pre-radiotherapy ambulatory status, other bone metastases, visceral metastases, time developing motor deficits before radiotherapy, and the radiation schedule.

Results: On multivariate analysis, better functional outcome was associated with absence of visceral metastases (estimate: 0.72; 95\%-confidence interval [Cl]: 0.07-1.36; $\mathrm{p}=0.030$ ) and a slower ( $>7$ days) development of motor deficits (estimate: 1.93; 95\%-Cl: 1.18-2.68; $\mathrm{p}<0.001$ ). Improved local control of MSCC was associated with absence of visceral metastases (risk ratio [RR]: 10.26; 95\%-Cl: 2.11-74.73; $p=0.004$ ). Improved survival was associated with favorable ECOG-PS (RR: 2.12; 95\%-Cl: 1.40-3.29; $p<0.001$ ), being ambulatory prior to radiotherapy (RR: 1.98; 95\%-Cl: 1.40-2.81; $p<0.001$ ), absence of visceral metastases (RR: 2.74; 95\%-Cl: 1.93-3.91; $p<0.001$ ), and slower development of motor deficits (RR: 1.27; 95\%-Cl: 1.07-1.51; $p=0.007$ ). Absence of other bone metastases showed a trend (RR: 1.38; 95\%-Cl: 0.98-1.95; $p=0.07)$.

Conclusions: This study identified additional independent prognostic factors for functional outcome, local control of MSCC, and survival after radiotherapy of MSCC from cancer of unknown primary. These prognostic factors can help select the best treatment regimen for each individual patient.
\end{abstract}

Keywords: Prognostic factors, Cancer of unknown primary, Metastatic spinal cord compression, Radiotherapy, treatment outcomes

\section{Background}

Up to $10 \%$ of adult cancer patients develop metastatic spinal cord compression (MSCC) during their disease $[1,2]$. Today the most common treatment modality used for MSCC is radiotherapy alone. The addition of upfront decompressive surgery to radiotherapy can improve the outcomes of those $10-15 \%$ of patients with MSCC, who have a favorable ECOG-PS, a relatively good survival prognosis, and a limited number of involved vertebrae $[2,3]$. To optimally take into account each patient's individual situation, it is mandatory to personalize the

\footnotetext{
* Correspondence: rades.dirk@gmx.net

'Department of Radiation Oncology, University of Lubeck, Lubeck, Germany Full list of author information is available at the end of the article
}

treatment approach as much as possible. Personalization of treatment can be facilitated if patients with MSCC from a particular type of primary tumor are regarded as a separate group of patients. Such an approach appears reasonable, because tumor entities can vary a lot regarding the prognosis of the disease and the biological behavior. Patients with MSCC from cancer of unknown primary demand particular attention, because they have a very poor survival prognosis when compared to patients with MSCC from other tumors [1,2]. Furthermore, these patients are relatively common and account for about $10 \%$ of all patients developing MSCC. This study aimed to identify independent prognostic factors for different endpoints including functional outcome,
Ciomed Central

(c) 2012 Douglas et al.; licensee BioMed Central Ltd. This is an Open Access article distributed under the terms of the Creative Commons Attribution License (http://creativecommons.org/licenses/by/2.0), which permits unrestricted use, distribution, and reproduction in any medium, provided the original work is properly cited. 
local control of MSCC, and survival in the largest series of patients with MSCC from cancer of unknown primary reported so far, in order to contribute to the personalization of the treatment of these patients.

\section{Results}

Of the 175 patients included in this study, 21 (12\%) showed an improvement, 96 (55\%) no further progression (no change), and 58 (33\%) deterioration of motor function ( $21 \%$ real deterioration plus $12 \%$ no improvement of complete paraplegia). Summarized in Table 1 are the results of the multivariate analysis of functional outcome. An improvement of motor function was significantly associated with absence of visceral metastases at the time of radiotherapy (estimate: 0.72 ; $95 \%$-confidence interval $[\mathrm{CI}]$ : 0.07-1.36; $\mathrm{p}=0.030)$ and slower $(>7$ days $)$ development of motor deficits prior to the start of radiotherapy (estimate: 1.93; 95\%-CI: 1.18-2.68; $\mathrm{p}<0.001$ ).

An improvement of local control of MSCC was associated with the absence of visceral metastases at the time of radiotherapy $(\mathrm{p}=0.001)$ in the univariate analysis. The results of the univariate analysis are summarized in Table 2. On multivariate analysis, improved local control was also significantly associated with absence of visceral metastases (risk ratio [RR]: 10.26; 95\%-CI: 2.11-74.73; $\mathrm{p}=0.004)$.

The median survival time was 4 months in the entire cohort (Figure 1). According to the univariate analysis of survival, improvement was associated with age $<65$ years $(\mathrm{p}=0.048)$, an ECOG-PS $2(\mathrm{p}<0.001)$, being ambulatory prior to radiotherapy $(\mathrm{p}<0.001)$, absence of other bone metastases at the time of radiotherapy $(p=0.005)$, absence of visceral metastases at the time of radiotherapy $(\mathrm{p}<0.001)$, and slower development of motor deficits prior to radiotherapy $(\mathrm{p}<0.001)$. The results of the univariate analysis of survival are summarized in Table 3. The multivariate analysis revealed four prognostic factors to be associated with improvement of survival: ECOG-PS 2 (RR: 2.12, 95\%-CI: 1.40-3.29, $\mathrm{p}<0.001$ ), being ambulatory (RR: $1.98,95 \%$-CI: $1.40-$ $2.81, \mathrm{p}<0.001$ ), the absence of visceral metastases (RR: 2.74, 95\%-CI: $1.93-3.91, \mathrm{p}<0.001)$ and the time developing motor deficits (RR: 1.27, 95\%-CI: 1.07-1.51, $\mathrm{p}=0.007)$. Absence of other bone metastases showed a trend (RR: $1.38 ; 95 \%-C I: 0.98-1.95 ; \mathrm{p}=0.07$ ). The results of the multivariate analysis of survival are shown in Table 4.

Acute radiation induced toxicity such as skin toxicity, nausea and diarrhea was mild, late toxicity such as myelopathy was not observed.

\section{Discussion}

The treatment for patients with MSCC should be planned by taking into account independent prognostic
Table 1 Impact of the potential prognostic factors on functional outcome

\begin{tabular}{|c|c|c|c|c|}
\hline & $\begin{array}{l}\text { Improveme } \\
\text { n (\%) }\end{array}$ & $\begin{array}{l}\text { t No chang } \\
\text { n (\%) }\end{array}$ & $\begin{array}{l}\text { Deterioration } \\
\text { n (\%) }\end{array}$ & p \\
\hline \multicolumn{5}{|l|}{ Age } \\
\hline$\leq 65$ years $(n=85)$ & $9(11)$ & $53(62)$ & $23(27)$ & \\
\hline$>65$ years $(n=90)$ & $12(13)$ & $43(48)$ & $35(39)$ & 0.54 \\
\hline \multicolumn{5}{|l|}{ Gender } \\
\hline Female $(n=53)$ & $8(15)$ & $27(51)$ & $18(34)$ & \\
\hline Male $(n=122)$ & $13(11)$ & $69(57)$ & $40(33)$ & 0.42 \\
\hline \multicolumn{5}{|l|}{ ECOG performance score } \\
\hline $2(n=49)$ & $10(20)$ & $29(59)$ & $10(20)$ & \\
\hline $3-4(n=126)$ & $11(9)$ & $67(53)$ & $48(38)$ & 0.25 \\
\hline \multicolumn{5}{|c|}{ Number of involved vertebrae } \\
\hline $1-2(n=55)$ & $8(15)$ & $35(64)$ & $12(22)$ & \\
\hline$\geq 3(n=120)$ & $13(11)$ & $61(51)$ & $46(38)$ & 0.84 \\
\hline \multicolumn{5}{|c|}{ Ambulatory status prior to RT } \\
\hline $\begin{array}{l}\text { Not Ambulatory } \\
(\mathrm{n}=89)\end{array}$ & $9(10)$ & $46(52)$ & $34(38)$ & \\
\hline Ambulatory $(n=86)$ & $12(14)$ & $50(58)$ & $24(28)$ & 0.21 \\
\hline \multicolumn{5}{|l|}{ Other bone metastases } \\
\hline No $(n=65)$ & $11(17)$ & $39(60)$ & $15(23)$ & \\
\hline Yes $(n=110)$ & $10(9)$ & $57(52)$ & $43(39)$ & 0.46 \\
\hline \multicolumn{5}{|l|}{ Visceral metastases } \\
\hline No $(n=86)$ & $15(17)$ & $34(40)$ & $37(43)$ & \\
\hline Yes $(n=89)$ & $6(7)$ & $62(70)$ & $21(24)$ & 0.030 \\
\hline \multicolumn{5}{|c|}{ Time developing motor deficits } \\
\hline 1-7 days $(n=88)$ & $4(5)$ & $38(43)$ & $46(52)$ & \\
\hline$>7$ days $(n=87)$ & $17(20)$ & $58(67)$ & $12(14)$ & $<0.001$ \\
\hline \multicolumn{5}{|l|}{ Radiation schedule } \\
\hline $\begin{array}{l}\text { Short-course RT } \\
(\mathrm{n}=90)\end{array}$ & $7(8)$ & $60(67)$ & $23(26)$ & \\
\hline $\begin{array}{l}\text { Longer-course RT } \\
(\mathrm{n}=85)\end{array}$ & $14(16)$ & $36(42)$ & $35(41)$ & 0.86 \\
\hline Entire cohort $(n=175)$ & $21(12)$ & $96(55)$ & $58(33)$ & \\
\hline
\end{tabular}

The $p$-values were obtained from the multivariate analysis performed with the ordered-logit model.

factors, which allow estimating the patient's prognosis. Prognostic factors that indicate the effect of radiotherapy on functional outcome are important to identify patients who appear adequately treated with radiotherapy alone, i.e. patients who have a high probability to maintain or regain the ability to walk after irradiation. Such prognostic factors can also identify patients who do not achieve a satisfying functional outcome with radiotherapy alone and, therefore, could benefit from upfront decompressive surgery in addition to radiotherapy. In randomized study of 101 highly selected patients that compared decompressive surgery followed by radiotherapy to radiotherapy alone, significantly more patients were able 
Table 2 Univariate analysis of local control of MSCC

\begin{tabular}{|c|c|c|c|}
\hline & $\begin{array}{l}\text { At } 6 \text { months } \\
(\%)\end{array}$ & $\begin{array}{l}\text { At } 12 \text { months } \\
\text { (\%) }\end{array}$ & p \\
\hline \multicolumn{4}{|l|}{ Age } \\
\hline$\leq 65$ years $(n=85)$ & 95 & 95 & \\
\hline$>65$ years $(n=90)$ & 92 & 61 & 0.13 \\
\hline \multicolumn{4}{|l|}{ Gender } \\
\hline Female $(n=53)$ & 96 & 96 & \\
\hline Male $(n=122)$ & 92 & 75 & 0.35 \\
\hline \multicolumn{4}{|l|}{ ECOG performance score } \\
\hline $2(n=49)$ & 98 & 83 & \\
\hline $3-4(n=126)$ & 88 & 88 & 0.44 \\
\hline \multicolumn{4}{|l|}{ Number of involved vertebrae } \\
\hline $1-2(n=55)$ & 98 & 82 & \\
\hline$\geq 3(n=120)$ & 90 & 82 & 0.27 \\
\hline \multicolumn{4}{|l|}{ Ambulatory status prior to RT } \\
\hline Not Ambulatory $(n=89)$ & 92 & 92 & \\
\hline Ambulatory $(n=86)$ & 93 & 80 & 0.54 \\
\hline \multicolumn{4}{|l|}{ Other bone metastases } \\
\hline No $(n=65)$ & 98 & 79 & \\
\hline Yes $(n=110)$ & 88 & 88 & 0.55 \\
\hline \multicolumn{4}{|l|}{ Visceral metastases } \\
\hline No $(n=86)$ & 98 & 91 & \\
\hline Yes $(n=89)$ & 86 & 43 & 0.002 \\
\hline \multicolumn{4}{|l|}{ Time developing motor deficits } \\
\hline 1-7 days $(n=88)$ & 89 & 89 & \\
\hline$>7$ days $(n=87)$ & 96 & 83 & 0.22 \\
\hline \multicolumn{4}{|l|}{ Radiation schedule } \\
\hline Short-course RT $(n=90)$ & 87 & 77 & \\
\hline Longer-course RT $(n=85)$ & 98 & 86 & 0.12 \\
\hline Entire cohort $(n=175)$ & 93 & 82 & \\
\hline
\end{tabular}

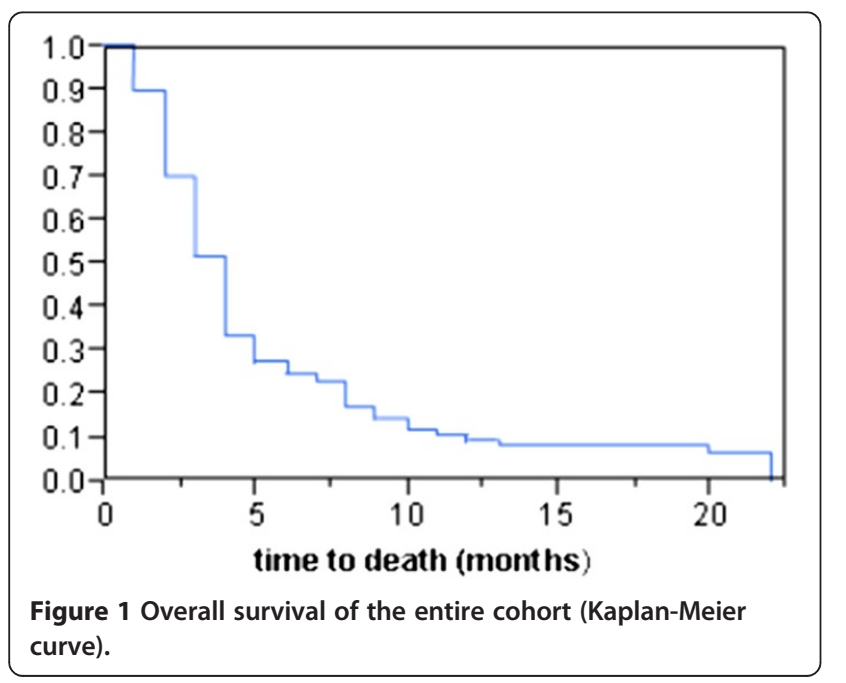

Table 3 Univariate analysis of survival

\begin{tabular}{|c|c|c|c|}
\hline & $\begin{array}{l}\text { At } 6 \text { months } \\
(\%)\end{array}$ & $\begin{array}{l}\text { At } 12 \text { months } \\
\text { (\%) }\end{array}$ & $p$ \\
\hline \multicolumn{4}{|l|}{ Age } \\
\hline$\leq 65$ years $(n=85)$ & 32 & 8 & \\
\hline$>65$ years $(n=90)$ & 19 & 12 & 0.048 \\
\hline \multicolumn{4}{|l|}{ Gender } \\
\hline Female $(n=53)$ & 26 & 13 & \\
\hline Male $(n=122)$ & 25 & 8 & 0.38 \\
\hline \multicolumn{4}{|l|}{ ECOG performance score } \\
\hline $2(n=49)$ & 53 & 24 & \\
\hline $3-4(n=126)$ & 14 & 4 & $<0.001$ \\
\hline \multicolumn{4}{|l|}{ Number of involved vertebrae } \\
\hline $1-2(n=55)$ & 33 & 9 & \\
\hline$\geq 3(n=120)$ & 22 & 10 & 0.13 \\
\hline \multicolumn{4}{|l|}{ Ambulatory status prior to RT } \\
\hline Not Ambulatory $(n=89)$ & 15 & 3 & \\
\hline Ambulatory $(n=86)$ & 36 & 17 & $<0.001$ \\
\hline \multicolumn{4}{|l|}{ Other bone metastases } \\
\hline No $(n=65)$ & 38 & 15 & \\
\hline Yes $(n=110)$ & 17 & 7 & 0.005 \\
\hline \multicolumn{4}{|l|}{ Visceral metastases } \\
\hline No $(n=86)$ & 45 & 16 & \\
\hline Yes $(n=89)$ & 6 & 3 & $<0.001$ \\
\hline \multicolumn{4}{|l|}{ Time developing motor deficits } \\
\hline 1-7 days $(n=88)$ & 10 & 1 & \\
\hline$>7$ days $(n=87)$ & 40 & 18 & $<0.001$ \\
\hline \multicolumn{4}{|l|}{ Radiation schedule } \\
\hline Short-course RT $(n=90)$ & 21 & 11 & \\
\hline Longer-course RT $(n=85)$ & 29 & 8 & 0.19 \\
\hline Entire cohort $(n=175)$ & 25 & 9 & \\
\hline
\end{tabular}

to walk after treatment in the surgery plus radiotherapy group ( $84 \%$ vs. $57 \%, \mathrm{p}=0.001)$ [3].

To be able to predict the patient's survival prognosis is also very important for the selection of the appropriate treatment regimen. Patients with a more favorable prognosis are likely to benefit from longer-course radiotherapy programs supplemented by bisphosphonate treatment rather than from short-course radiotherapy. This is because short-course radiotherapy results in worse local control of MSCC, which becomes more of an issue in patients surviving 6 months or longer following treatment $[4,5]$. Prognostic factors that allow predict survival are important also for identifying patients with a very poor survival prognosis, for whom a short-course radiotherapy would be a better option in order to avoid unnecessary distress for these often debilitated patients. 
Table 4 Multivariate analysis of survival (Cox proportional hazards model)

\begin{tabular}{|c|c|c|c|}
\hline & Risk ratio & $\begin{array}{l}\text { 95\%- confidence } \\
\text { interval }\end{array}$ & $p$ \\
\hline \multicolumn{4}{|l|}{ Age } \\
\hline ( $\leq 65$ vs. $>65$ years) & 1.14 & $0.83-1.58$ & 0.42 \\
\hline \multicolumn{4}{|l|}{ ECOG performance score } \\
\hline (2 vs. 3-4) & 2.12 & $1.40-3.29$ & $<0.001$ \\
\hline \multicolumn{4}{|l|}{ Ambulatory status prior to RT } \\
\hline (ambulatory vs. ot ambulatory) & 1.98 & $1.40-2.81$ & $<0.001$ \\
\hline \multicolumn{4}{|l|}{ Other bone metastases } \\
\hline (no vs. yes) & 1.38 & $0.98-1.95$ & 0.07 \\
\hline \multicolumn{4}{|l|}{ Visceral metastases } \\
\hline (no vs. yes) & 2.74 & $1.93-3.91$ & $<0.001$ \\
\hline \multicolumn{4}{|l|}{ Time developing motor deficits } \\
\hline (>7 vs. $1-7$ days & 1.27 & $1.07-1.51$ & 0.007 \\
\hline
\end{tabular}

This study aimed to identify prognostic factors for both functional outcome and survival, because both endpoints are important in order to choose the most appropriate treatment regimen for the individual patient with MSCC from cancer of unknown primary. The multivariate analysis of functional outcome revealed that patients who had visceral metastases at the time of radiotherapy and experienced a rapid development of motor deficits prior to radiotherapy had an unfavorable functional outcome. These findings agree with our previous report on MSCC from cancer of unknown primary published five years ago [6]. The finding that a rapid development of motor deficits was associated with a worse functional outcome could be explained by the fact that a rapid decline in motor function was caused by disruption of the arterial blood flow resulting in spinal cord infarction $[7,8]$. In contrast, a slower decline in motor function was most likely a result of venous congestion, which was reversible in many cases. In our present study, $21 \%$ of the patients showed a deterioration of motor function after radiotherapy alone, and $12 \%$ did not improve after complete paraplegia. In a recent retrospective study of 51 patients who received surgical management of MSCC from CUP, deterioration was observed only in $6 \%$ of patients [9]. Therefore, it appears that a considerable proportion of patients with MSCC from cancer of unknown primary may be considered for decompressive surgery, in particular those patients with a rapid development of motor deficits or visceral metastases who do not have an extraordinarily poor survival prognosis.

Prognostic factors predicting the patient's survival prognosis are important in two ways. They can help identify patients who may not be candidates for decompressive surgery because they have a very poor survival prognosis, although functional outcome following radiotherapy alone is not expected to be satisfying. Furthermore, the estimated survival time has an impact on the selection of the radiotherapy regimen. In the present study, survival was negatively associated with four prognostic factors indicating an advanced and rapidly progressing disease: poor performance status, being not ambulatory prior to radiotherapy, presence of visceral metastases, and rapid development of motor deficits prior to radiotherapy. Patients with these negative predictors may receive short-course radiotherapy to avoid that these patients have to spend a considerable part of their remaining life time with treatment. In the group of patients $(n=28)$ with all four negative prognostic factors, the 6 -month survival rate was only $4 \%$. These patients may be candidates for single-fraction radiotherapy or best supportive care.

The prognostic value of the ECOG-PS has not been observed in our previous study published five years ago and can, therefore, be considered a new prognostic factor for patients with MSCC from cancer of unknown primary [6]. Potential prognostic factors for local control of MSCC have not yet been investigated in patients with MSCC from cancer of unknown primary at all. Therefore, the present study provides new and important results in addition to our previous report. However, the retrospective nature of this study must be taken into account during the interpretation of the results. Retrospective studies always bear the risk of hidden selection biases. However, a prospective study will be difficult to perform in patients with MSCC from cancer of unknown primary, as it will take several years to include a sufficiently large number of such patients.

\section{Conclusions}

The present study identified independent prognostic factors for functional outcome, local control of MSCC, and survival in patients with MSCC from cancer of unknown primary. These prognostic factors can guide physicians to decide which is the most appropriate treatment regimen for the individual patient. During such a decision making process the questions whether decompressive surgery may be a reasonable option and whether shortcourse or longer-course radiotherapy is more appropriate should be adressed.

\section{Methods}

The data of 175 patients irradiated for MSCC from cancer of unknown primary between 1991 and 2011 were retrospectively reviewed. The patients had to fulfill the following criteria to be included in this analysis: motor deficits of the lower extremities caused by metastatic compression of the thoracic or lumbar spinal cord, confirmation of the diagnosis with spinal computed tomography or magnet resonance imaging, and no 
previous surgery or radiotherapy within the involved parts of the spinal cord. The patients were given a daily dexamethasone dose between $3 \times 4 \mathrm{mg}$ and $4 \times 8 \mathrm{mg}$ from the first day of radiotherapy and then at least for another week. The patients were generally presented to a neurosurgeon or an orthopedic surgeon to discuss whether upfront decompressive surgery may be a reasonable option or not. Patients were generally not considered for surgery if they had a poor performance status (ECOG 3-4), involvement of several spinal sites, severe neurologic deficits (paraplegia) for longer than 48 hours, and a poor expected survival in case of multiple extraosseous lesions. Only $10 \%$ of the patients who presented with MSCC from CUP were considered candidates for surgery. The data were collected from the patients themselves, their files, and their general practitioners or treating oncologists. Because this study did not report on a clinical trial, and because the data were retrospective in nature and analyzed anonymously, approval by an ethic committee was not necessary. The patient characteristics are summarized in Table 5.

Every participating center contributed an unselected series of patients with MSCC treated within a specific time period. The energy used for irradiation varied between 6-10 MeV photons, and the planning target volume included one uninvolved vertebra above and below the metastatic lesions. Motor function was assessed right before the start of radiotherapy, as well as at one month, three months and six months after radiotherapy was completed. To categorize motor function we used a 5point scale: Grade 0: normal strength; Grade 1: ambulatory without aid, Grade 2: ambulatory with aid, Grade 3: not ambulatory, Grade 4: paraplegia [10]. If the patient's motor function was rated as improved or deteriorated, an alteration of at least one point on the 5-point scale must have had occurred. Patients who presented with complete paraplegia and did not approve were rated as deteriorated.

The following nine potential prognostic factors were investigated with respect to post-radiotherapy motor function, local control of MSCC, and survival: age ( $\leq 65$ vs. $>65$ years), gender, Eastern Cooperative Oncology Group performance score (ECOG-PS 2 vs. 3-4), number of involved vertebrae (1-2 vs. 3), pre-radiotherapy ambulatory status (not ambulatory vs. ambulatory), other bone metastases at the time of radiotherapy (no vs. yes), visceral metastases at the time of radiotherapy (no $v s$. yes), time developing motor deficits before radiotherapy (1-7 vs. $>7$ days), and the radiotherapy schedule (shortcourse radiotherapy with $1 \times 8$ Gy or $5 \times 4$ Gy in 1 week $v s$. longer-course radiotherapy with $10 \times 3$ Gy in 2 weeks, $15 \times 2.5$ Gy in 3 weeks, or $20 \times 2$ Gy in 4 weeks).

The nine potential prognostic factors for functional outcome were included in a multivariate analysis
Table 5 Patient characteristics

\begin{tabular}{|c|c|c|}
\hline & $\mathrm{N}$ patients & Proportion (\%) \\
\hline \multicolumn{3}{|l|}{ Age } \\
\hline$\leq 65$ years & 85 & 49 \\
\hline$>65$ years & 90 & 51 \\
\hline \multicolumn{3}{|l|}{ Gender } \\
\hline Female & 53 & 30 \\
\hline Male & 122 & 70 \\
\hline \multicolumn{3}{|c|}{ ECOG performance score } \\
\hline 2 & 49 & 78 \\
\hline $3-4$ & 126 & 72 \\
\hline \multicolumn{3}{|c|}{ Number of involved vertebrae } \\
\hline $1-2$ & 55 & 31 \\
\hline$\geq 3$ & 120 & 69 \\
\hline \multicolumn{3}{|c|}{ Ambulatory status prior to RT } \\
\hline Not Ambulatory & 89 & 51 \\
\hline Ambulatory & 86 & 49 \\
\hline \multicolumn{3}{|l|}{ Other bone metastases } \\
\hline No & 65 & 37 \\
\hline Yes & 110 & 63 \\
\hline \multicolumn{3}{|l|}{ Visceral metastases } \\
\hline No & 86 & 49 \\
\hline Yes & 89 & 51 \\
\hline \multicolumn{3}{|c|}{ Time developing motor deficits } \\
\hline $1-7$ days & 88 & 50 \\
\hline$>7$ days & 87 & 50 \\
\hline \multicolumn{3}{|l|}{ Radiation schedule } \\
\hline Short-course RT & 90 & 51 \\
\hline Longer-course RT & 85 & 49 \\
\hline
\end{tabular}

performed with the ordered-logit model, because these data were ordinal $(-1=$ deterioration, $0=$ no change, $1=$ improvement of motor function). Local control was defined as no recurrence or progression of MSCC in the irradiated spinal region. The diagnosis of an in-field recurrence of MSCC was confirmed by computed tomography or magnet resonance imaging. Local control and survival rates were calculated with the Kaplan-Meiermethod [11]. The differences between the Kaplan-Meier curves were calculated with the log-rank test. The prognostic factors found to be significant $(\mathrm{p}<0.05)$ in the univariate analysis were included in a multivariate analysis, performed with the Cox proportion hazards model. Patients were followed until death or for median 7.5 months (range: 6-20 months) in those alive at the last follow-up visit.

\section{Abbreviations}

ECOG: Eastern cooperative oncology group; ECOG-PS: Eastern cooperative oncology group performance score; Gy: Gray; MeV: Mega electron volts; MSCC: Metastatic spinal cord compression; RT: Radiotherapy. 


\section{Competing interests}

The authors declare that they have no competing interests.

\section{Author details}

${ }^{1}$ Department of Radiation Oncology, University of Lubeck, Lubeck, Germany. ${ }^{2}$ Department of Radiation Oncology, University Medical Center HamburgEppendorf, Hamburg, Germany. 'Department of Radiation Oncology, Saad Specialist Hospital Al-Khobar, Al-Khobar, Saudi Arabia. ${ }^{4}$ Department of Radiation Oncology, Mayo Clinic Scottsdale, Scottsdale, AZ, USA.

\section{Authors' contributions}

SD, SES and DR participated in the design of the study. VR and SES performed the statistical analyses. SD, SH, AB and DR provided study material. All authors were involved in manuscript writing; they read and approved the final manuscript.

Received: 29 February 2012 Accepted: 21 June 2012

Published: 21 June 2012

\section{References}

1. Prasad D, Schiff D: Malignant spinal cord compression. Lancet Oncol 2005, 6:15-24.

2. Rades $D, A b r a h m ~ J L$ : The role of radiotherapy for metastatic epidural spinal cord compression. Nat Rev Clin Oncol 2010, 7:590-598.

3. Patchell R, Tibbs PA, Regine WF, Payne R, Saris S, Kryscio RJ, Mohiuddin M, Young B: Direct decompressive surgical resection in the treatment of spinal cord compression caused by metastatic cancer: a randomised trial. Lancet 2005, 366:643-648.

4. Rades D, Fehlauer F, Schulte R, Veninga T, Stalpers LJ, Basic H, Bajrovic A, Hoskin PJ, Tribius S, Wildfang I, Rudat V, Engenhart-Cabilic R, Karstens JH, Alberti W, Dunst J, Schild SE: Prognostic factors for local control and survival after radiotherapy of metastatic spinal cord compression. J Clin Oncol 2006, 24:3388-3393.

5. Rades D, Lange M, Veninga T, Stalpers $\sqcup$, Bajrovic A, Adamietz IA, Rudat V, Schild SE: Final results of a prospective study comparing the local control of short-course and long-course radiotherapy for metastatic spinal cord compression. Int J Radiat Oncol Biol Phys 2011, 79:524-530.

6. Rades D, Fehlauer F, Veninga T, Stalpers LJ, Basic H, Hoskin PJ, Rudat V, Karstens JH, Schild SE, Dunst J: Functional outcome and survival after radiotherapy of metastatic spinal cord compression in patients with cancer of unknown primary. Int J Radiat Oncol Biol Phys 2007, 67:532-537.

7. Ushio Y, Posner R, Posner JB, Shapiro WR: Experimental spinal cord compression by epidural neoplasms. Neurology 1977, 27:422-429.

8. Manabe S, Tanaka H, Higo Y, Park P, Ohno T, Tateishi A: Experimental analysis of the spinal cord compressed by spinal metastasis. Spine 1989, 14:1308-1315.

9. Aizenberg MR, Fox BD, Suji D, McCutcheon IE, Rao G, Rhines LD: Surgical management of unknown primary tumors metastatic to the spine. J Neurosurg Spine 2012, 16:86-92.

10. Tomita T, Galicich JH, Sundaresan N: Radiation therapy for spinal epidural metastases with complete block. Acta Radiol Oncol 1983, 22:135-143.

11. Kaplan EL, Meier P: Non parametric estimation from incomplete observations. J Am Stat Assoc 1958, 53:457-481.

\section{Submit your next manuscript to BioMed Central and take full advantage of:}

- Convenient online submission

- Thorough peer review

- No space constraints or color figure charges

- Immediate publication on acceptance

- Inclusion in PubMed, CAS, Scopus and Google Scholar

- Research which is freely available for redistribution 